\title{
Family level variation in Wolbachia- mediated dengue virus blocking in Aedes aegypti
}

\author{
Gerard Terradas ${ }^{1}$, Scott L. Allen², Stephen F. Chenoweth ${ }^{2}$ and Elizabeth A. McGraw ${ }^{\text {** }}$
}

\begin{abstract}
Background: The mosquito vector Aedes aegypti is responsible for transmitting a range of arboviruses including dengue (DENV) and Zika (ZIKV). The global reach of these viruses is increasing due to an expansion of the mosquito's geographic range and increasing urbanization and human travel. Vector control remains the primary means for limiting these diseases. Wolbachia pipientis is an endosymbiotic bacterium of insects that has the ability to block the replication of pathogens, including flaviviruses such as DENV or ZIKV, inside the body of the vector. A strain of Wolbachia called wMel is currently being released into wild mosquito populations to test its potential to limit virus transmission to humans. The mechanism that underpins the virus blocking effect, however, remains elusive.

Methods: We used a modified full-sib breeding design in conjunction with vector competence assays in wildtype and wMel-infected Aedes aegypti collected from the field. All individuals were injected with DENV-2 intrathoracically at 5-6 days of age. Tissues were dissected 7 days post-infection to allow quantification of DENV and Wolbachia loads.

Results: We show the first evidence of family level variation in Wolbachia-mediated blocking in mosquitoes. This variation may stem from either genetic contributions from the mosquito and Wolbachia genomes or environmental influences on Wolbachia. In these families, we also tested for correlations between strength of blocking and expression level for several insect immunity genes with possible roles in blocking, identifying two genes of interest (AGO2 and SCP-2).

Conclusions: In this study we show variation in Wolbachia-mediated DENV blocking in Aedes aegypti that may arise from genetic contributions and environmental influences on the mosquito-Wolbachia association. This suggests that Wolbachiamediated blocking may have the ability to evolve through time or be expressed differentially across environments. The long-term efficacy of Wolbachia in the field will be dependent on the stability of blocking. Understanding the mechanism of blocking will be necessary for successful development of strategies that counter the emergence of evolved resistance or variation in its expression under diverse field conditions.
\end{abstract}

Keywords: Aedes, Genetic variation, Wolbachia, Dengue virus, Evolution

\section{Background}

Wolbachia pipientis is an insect endosymbiont capable of manipulating host reproductive success via different mechanisms, the primary and most studied being cytoplasmic incompatibility (CI) [1]. CI gives Wolbachia-infected females a reproductive advantage and because the symbiont is maternally transmitted, the bacterium spreads rapidly through uninfected populations. Wolbachia also

\footnotetext{
* Correspondence: eam7@psu.edu

${ }^{1}$ School of Biological Sciences, Monash University, Clayton, Melbourne, VIC, Australia

Full list of author information is available at the end of the article
}

reduces susceptibility of their hosts to a range of pathogens, including viruses, other bacteria, nematodes, fungi and the malaria parasite [2-6]. The traits of $\mathrm{CI}$ and $\mathrm{Wol}$ bachia-mediated pathogen blocking together form the basis of emerging strategies to use Wolbachia as an agent of biocontrol against vector-borne diseases [7]. Though present in an estimated $40 \%$ of all insect species [8], Wolbachia is naturally absent in the main dengue vector, Ae aegypti. However, stably inherited Wolbachia infections with a range of strains ( $w$ Mel \& wMelPop originally from Drosophila melanogaster and wAlbB from Aedes albopictus) have been created in the mosquito using 
microinjection techniques [9-11]. Adult Ae. aegypti mosquitoes infected with $w \mathrm{Mel}[12]$ and $w \mathrm{AlB}[9]$ are currently being released into the wild to test the ability of Wolbachia to spread and to limit human disease [13].

Natural Ae. aegypti populations vary in their susceptibilities to dengue virus (DENV) [14-18] and laboratorybased breeding experiments have demonstrated substantial contribution of the mosquito genome to variation in susceptibility often through the innate immune response [17, 19-21]. When Wolbachia infection is present, pathogen blocking is exhibited by reductions in viral infection rates, loads and transmissibility [5, 22-25] beyond the wildtype host's natural antiviral mechanisms. Wolbachia's presence throughout the body of the mosquito $[5,11]$ provides numerous opportunities for the symbiont to interfere with the successful colonization and replication of viruses. Inside cells, Wolbachia lives within a vacuole of host origin $[26,27]$ utilizing transporters to feed off host resources like amino acids that its incomplete genome cannot synthesize $[28,29]$, and communicating with the extracellular environment using a Type IV secretion system [30, 31]. Wolbachia-mediated phenotypes including pathogen blocking must therefore, by necessity, be enacted via host physiologies and across host membranes. We would therefore predict that variation in the mosquito genome is likely to play a role in Wolbachia-mediated blocking.

It is unclear whether the Wolbachia genome evolves fast enough to be a substantial contributor to variation in the trait. Each generation the population of inherited symbiont experiences a bottleneck at the point of transmission via the embryo [32, 33] and there is little opportunity to exchange genes with diverse Wolbachia strains in the intracellular environment [34]. In the case of stable transinfection of the $w$ MelPop strain into $A e$. aegypti no new substitutions were witnessed in the symbiont genome in the 4-year period post-introduction [35]. Changes have been demonstrated however in a Wolbachia strain's effects on Drosophila simulans over a longer timeframe [36, 37].

Understanding the mechanistic underpinning of the blocking trait, and in particular its complexity, is necessary to assess the role that genetic variation and evolution may play in shaping the trait's expression in the field. Various theories have arisen with regard to mechanism [38]. The first theory suggested that Wolbachia may "prime" or activate the host immune response, leading to a heightened ability to limit the growth and replication of subsequent infections with pathogens [4, 22, 39-41]. While there is growing evidence that immune priming may provide blocking against bacterial pathogens [42], innate immunity may only offer a small boost in viral blocking $[43,44]$. A second set of theories relate to competition for resources between Wolbachia and incoming pathogens. The resources have included intracellular space $[5,45]$, lipids $[26,46,47]$ and nitrogen [48]. Nitrogen may serve as a primary source of energy for Wolbachia [48] and Wolbachia's modulation of lipid profiles in insect cells may create an environment that is antagonistic toward viral replication [47]. A third set of studies suggests that Wolbachia may manipulate expression of host genes that control viruses via microRNAs [49-51]. Most recently, several studies have indicated that Wolbachia infection may alter fundamental structures [52] or environments in the host cell [53] that prevent viral replication immediately after entry into cells. A trend that is compatible with all of the above mechanistic explanations for blocking is that higher Wolbachia loads are associated with stronger blocking [11, 54-56].

As the Wolbachia genome is intimately tied to that of the host through maternal inheritance, it is difficult to tease apart the independent genetic contributions of the partners to the trait [43]. In the ideal experimental scenario, we could partition the relative contribution of the mosquito and Wolbachia genomes as well as the role of the environment in determining variation in DENV blocking. Such traditional quantitative breeding approaches would require the same mosquito families to be studied with and without Wolbachia infection. As transinfection of mosquitoes often requires injection of thousands of individuals to achieve success [10] and removal of Wolbachia by antibiotic treatment takes multiple generations [57], the ideal experiment cannot be done. Instead, we have used a modified full-sib breeding design approach to assess family level variation in Wolbachia-mediated blocking in a population of Australian Ae. aegypti. By examining the same trait in parallel in Wolbachia-free mosquito families we were also able to demonstrate the additional contribution (both genotypic and environmental) of Wolbachia infection to the variance of dengue virus load. We then used families exhibiting the phenotypic extremes in DENV blocking to screen four candidate mosquito genes for correlations in expression that would be suggestive of a functional role in blocking. We used qPCR gene screening as a proof of principle to see whether we could detect relationships between gene expression behavior and strength of Wolbachia-mediated blocking. The candidates tested were selected because they had previously been shown to be modulated by Wolbachia and also play a role in DENV infections.

\section{Results}

DENV load in head tissue by family

Breeding in a modified full-sib [58, 59] framework yielded 25 wildtype and 33 wMel-infected Ae. aegypti families with sufficient offspring for injections. For each family 5 to 30 females were injected with DENV-2 and 
then their midgut, head and carcass (representing the rest of the body) were dissected at 7-8 days postinfection (dpi). After RNA extraction of 5+ individual heads per family, DENV-2 load was quantified via RTqPCR. Head DENV loads have been commonly used as a proxy for dissemination of the virus $[11,60,61]$ and so we used them to rank families (Fig. 1). Carcasses from the selected individuals were then used to test for Wolbachia loads and gene expression analyses. All individuals for both WT and $w$ Mel lines were infected given the use of intrathoracic injection that bypasses the midgut infection barrier and allows the virus to disseminate freely. As expected, due to the action of blocking, DENV loads were lower in $w$ Mel families compared to WT $(t=31.94, d f=340, P<0.0001)$. Heritabililties for DENV load were high and significantly greater than zero for each line; WT $\left[\mathrm{H}^{2}=0.95\right.$ (0.54-1.29), LRT: $\chi^{2}=38.4$, $\left.P=5.76 \times 10^{-10}\right]$ and $w \mathrm{Mel}\left[\mathrm{H}^{2}=0.85(0.51-1.23)\right.$, LRT: $\left.X^{2}=70.0, P=1.11 \times 10^{-6}\right]$. Given the maternal inheritance of Wolbachia, the latter estimate will be highly inflated, suggesting greater similarity across families due to shared environmental variation and linkage of host and Wolbachia genomes. The slightly lower heritability may suggest that Wolbachia infection and its interaction with the host is introducing additional variation compared to the simple system involving the vector and virus alone.

\section{DENV load in carcass tissue by family}

To determine if the differences seen in DENV loads for the heads correspond to similar differences in carcasses, RNA extractions were performed on carcasses from individuals previously classified as extreme families (Low and High, Fig. 1). Carcass DENV loads mostly recapitulated the patterns seen in heads (Fig. 2, Additional file 1: Figure S1) and for each treatment we selected 6 families that were most concordant for subsequent analysis (Fig. 2). A generalized nested mixed model was used to test for differences between low and high clusters. Wolbachia infection status $\left(F_{(1)}=15.32, P=0.001\right)$, DENV load $\left(F_{(1)}=26.39, P<0.001\right)$ as well as the interaction between these two main factors and family $\left(F_{(21)}=9.47, P<0.001\right)$ were significant. The significant interaction is due to the higher range of DENV loads in WT families, given pathogen blocking in the $w$ Mel line.

\section{Wolbachia correlation to DENV titres}

To assess the variability of Wolbachia densities amongst families as well as a possible Wolbachia-based determination of DENV loads, gDNA was extracted from 3 individual carcasses per family and Wolbachia levels were checked using qPCR. As mean Wolbachia densities rise in families, DENV loads decline (Fig. 3). This negative correlation was significant (Additional file 1: Figure S2; $r=0.546, P<0.0001)$ and may indicate greater protection against DENV dissemination in the carcass in response to Wolbachia. Virus infection did not have an effect on Wolbachia loads (Additional file 1: Figure S3, $P=0.16)$.

\section{Candidate gene expression: immunity}

Having confirmed that the $w$ Mel strain reduces DENV replication at an individual and population level, we then used our families with extreme blocking phenotypes to test for associations with expression of immunity genes with potential roles in blocking (Figs. 4 and 5). We focused on vir-1 and $A G O 2$, genes that represent the two major antiviral pathways in mosquitoes, JAK/STAT and RNAi, respectively [62]. The latter gene has been shown to play a minor role in DENV blocking in mosquito cells [44]. Gene expression was analyzed using a generalized mixed model with the random variable 'Family' nested with Wolbachia $\times$ DENV load, with Wolbachia and DENV load as fixed factors. The effect of Wolbachia infection was significant (Fig. 4; $F_{(1)}=12.83, P=0.002$ ), causing upregulation in the expression of vir-1. However, vir-1 expression was not associated with DENV load/family (Fig. 4; $F_{(1)}=3.1, P=0.091$ ). There was also no significant interaction between the two main factors $\left(F_{(21)}=1.05, P=0.412\right.$, Additional file 1: Figure S4a). These results suggest that while vir-1 levels may be important for DENV control in the mosquito they do not explain variation in the blocking trait in Wolbachia-infected mosquitoes at least at the time point surveyed post-infection.

The same mixed effects model was applied to test for differences in argonaute-2 (AGO2) gene expression levels. The effect of Wolbachia was significant (Fig. 5; $\left.F_{(1)}=16.72, P=0.001\right)$, leading to heightened expression of the gene. We also detected a significant effect of DENV load/family (Fig. 5; $F_{(1)}=27.62, P<0.001$ ), demonstrating higher expression of the gene in Low DENV load families. The interaction was also significant $\left(F_{(21)}=5.26, P<0.001\right)$, showing that the differences between High and Low DENV loads in AGO2 expression are greater in $w$ Mel-infected mosquitoes than in WT (Additional file 1: Figure S4b). In WT families, gene expression decreases as DENV titres increase. The same is true for $w \mathrm{Mel}$-infected families, but with an even greater disparity between Low and High families.

\section{Candidate gene expression: host factor competition}

We also examined how genes involved in intracellular lipid transport (Sterol carrier protein 2, SCP-2) and nitric oxide biosynthesis (Nitric oxide synthase, NOS) are differentially expressed for each cell line and cluster. These genes have previously been proposed as not only important for lipid distribution or nitrogen production but also 

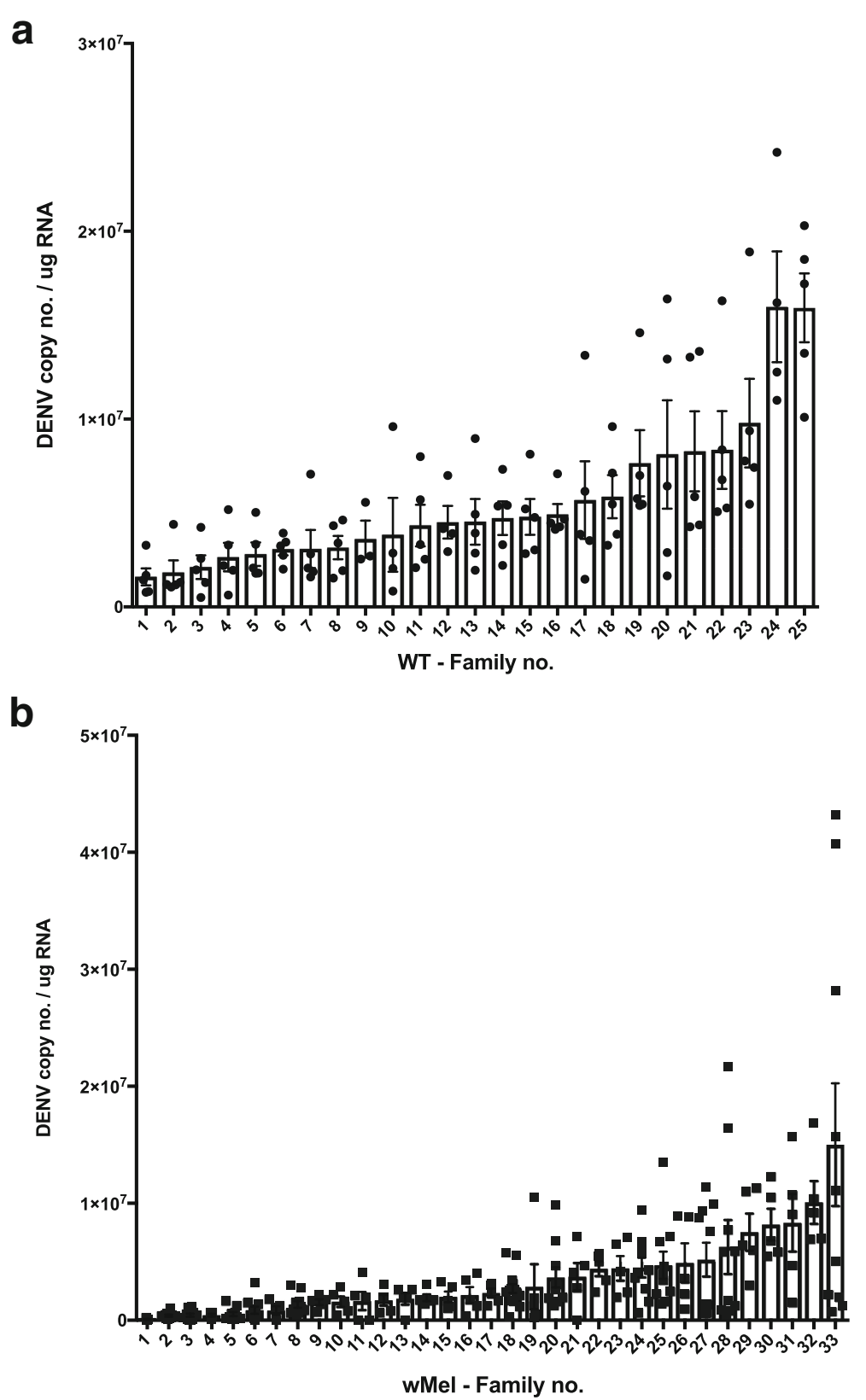

Fig. 1 Head DENV load. WT (a) and wMel-infected (b) families with mean and SEM depicted

to be critical for DENV infection in Ae. aegypti [63, 64]. The bacterium and the virus are hypothetically competing for host nutrients and thus providing the host with a Wolbachia-mediated blocking phenotype.

The effect of Wolbachia infection on SCP-2 expression was significant (Fig. 6; $F_{(1)}=5.01, P=0.035$ ), with $S C P$ 2 expression slightly down regulated in $w$ Mel mosquitoes relative to WT. We also see a significant DENV load effect on gene expression (Fig. 6; $F_{(1)}=64.91$, $P<0.001)$. In this case, contrary to what we see in AGO2 expression, SCP-2 levels are higher in those individuals clustered into High DENV Load for both WT and $w$ Mel-infected mosquitoes and hence the interaction was not significant (Additional file 1: Figure S4c; $\left.F_{(21)}=1.5, P=0.087\right)$. This suggests that while $S C P-2$ may be a contributing factor to viral success in mosquitoes, its expression is not associated with variation in $w$ Mel-mediated blocking.

For NOS, neither Wolbachia infection (Fig. 7; $\left.F_{(1)}=0.48, P=0.491\right)$ nor DENV load (Fig. $7, F_{(1)}=1.3$, $P=0.267)$ had an effect on the gene's expression. However, the interaction was significant (Fig. $7, F_{(21)}=3.73$, 


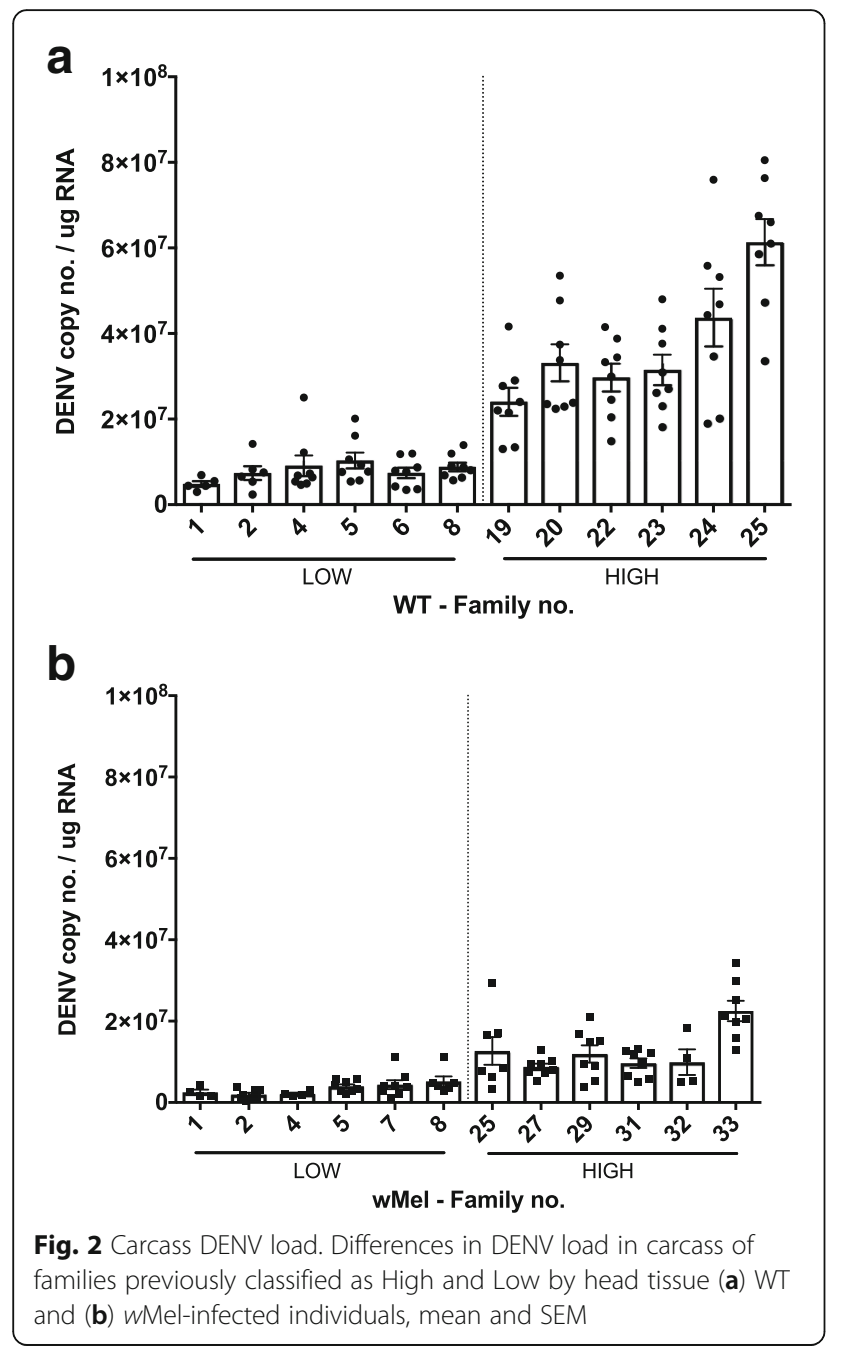

$P<0.001)$. The nature of the interaction is difficult to interpret given the high level of variation in expression between families particularly for the WT line (Fig. 7, Additional file 1: Figure S4d). These data would suggest that NOS expression is unlikely to be associated with Wolbachia-mediated blocking.

\section{Discussion}

In this study we aimed to measure family level variation present in the Wolbachia-mediated pathogen blocking trait in mosquitoes infected with the $w \mathrm{Mel}$ strain. To do so, we performed a modified full-sib breeding design that allowed us limit the contribution of environmental variation to the trait but not completely remove it given the maternal inheritance in Wolbachia. We were then able to use families representing the phenotypic extremes in blocking to test for correlations in gene expression for a number of candidate genes for the basis of the trait.

The experiments demonstrate that there is greater variation in DENV loads in the $w \mathrm{Mel}$-infected mosquitoes compared to wildtype mosquitoes. The DENV loads in extreme families of $w \mathrm{Mel}$ mosquitoes spanned 45-fold compared to the 5-fold difference seen for WT. DENV infection success in WT mosquitoes is highly influenced by genotype:genotype interactions between mosquito and virus $[17,60,65]$. The greater variation in $w \mathrm{Mel}$ mosquitoes may stem from contributions from the Wolbachia genome, as well environmental influences on the symbiont, confounded with family. Variation in pathogen blocking due to differences in Wolbachia strains has been demonstrated previously in Drosophila [66].

Studies that have examined phenotypic variation in blocking in both Ae. aegypti and Drosophila also show correlations between Wolbachia density and the

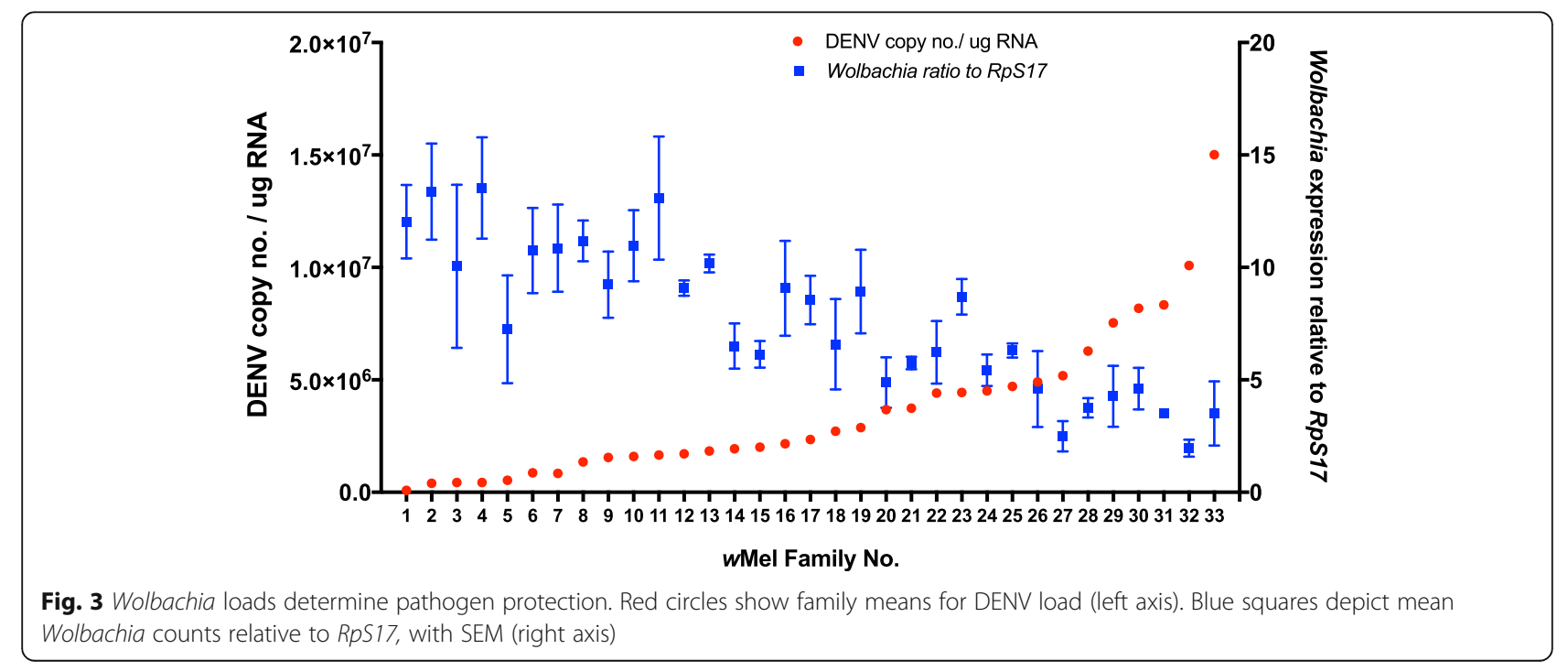




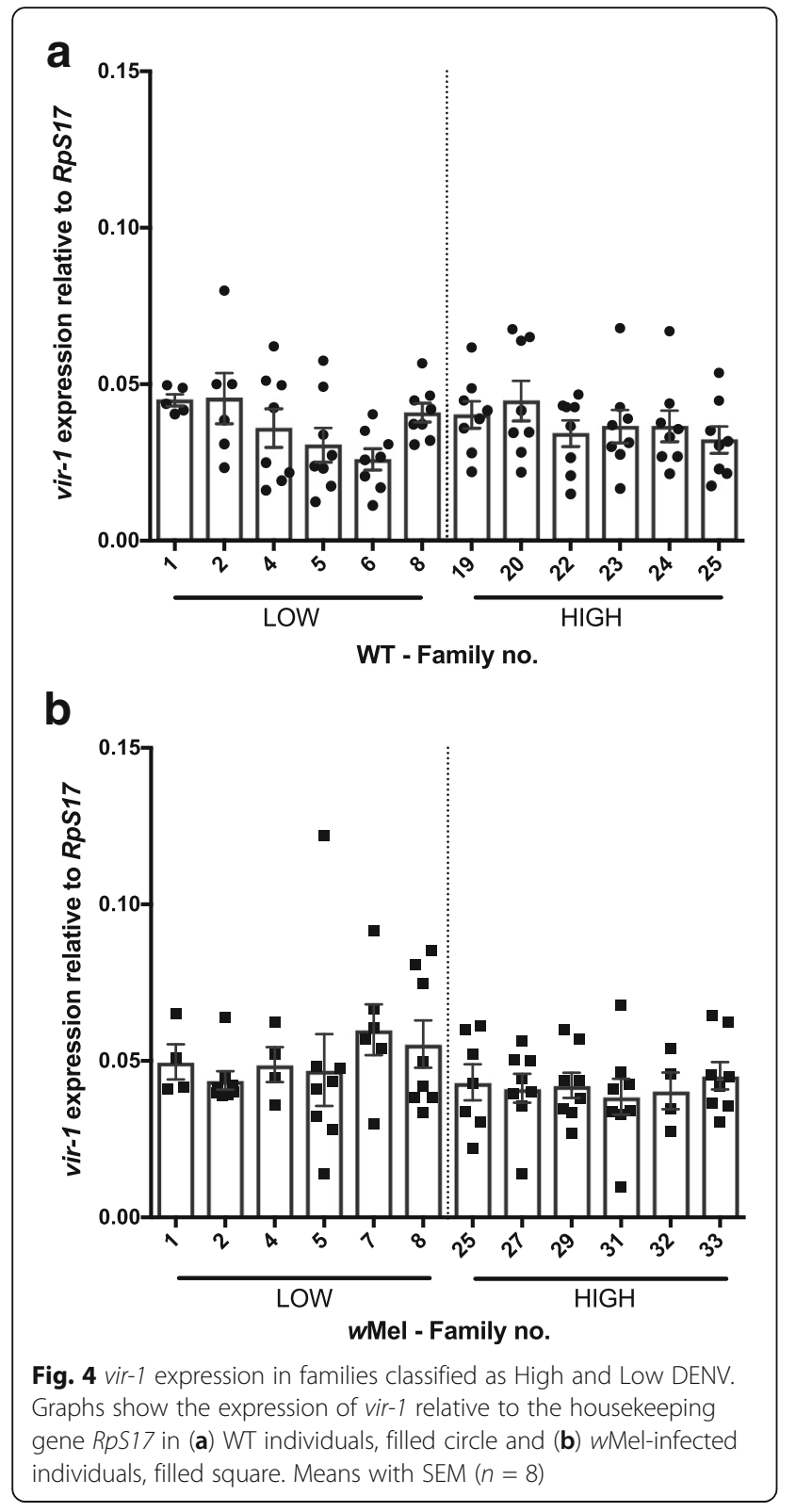

strength of pathogen blocking [5, 11, 54, 66, 67]. Therefore, after determining the blocking phenotype in the families, we also examined the variation in Wolbachia load for the wMel-infected population. We observed a high degree of variability in Wolbachia levels among families. Within families this measure will be confounded or inflated by Wolbachia's near perfect mode of vertical transmission. Wolbachia loads in the carcass also correlated with pathogenblocking ability as predicted. While recent work from our group suggested that Wolbachia loads in particular tissues may not determine blocking strength [68], our study reaffirms the relationship for total Wolbachia loads.

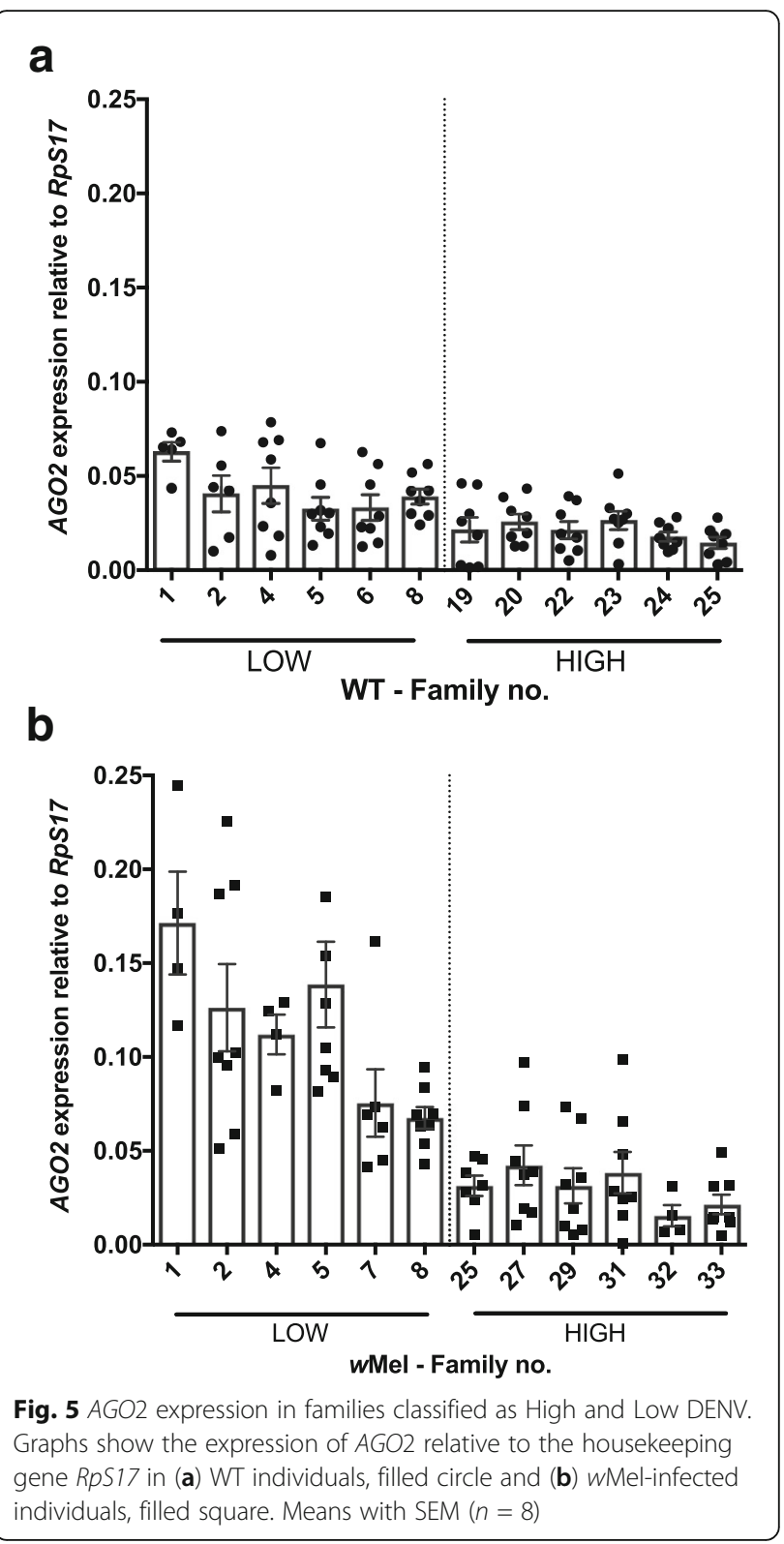

Wolbachia is currently being assessed for its capacity to limit dengue virus transmission from mosquitoes to humans in the field $[12,69,70]$. The long-term efficacy of Wolbachia is not only reliant on the effective spread of the symbiont in the population but also dependent on the stability of expression of the blocking trait. Understanding how much variation and in particular genetic variation there is for blocking and Wolbachia load is critical. This is because populations can only adapt and change if there is genetic variation present for the trait of interest [71]. Blocking may be expected to vary across genetically diverse mosquito populations, in response to diverse viruses, over a range of environmental conditions and with sufficient co-evolutionary time in response to diverging Wolbachia strains. Given genetic variation in 


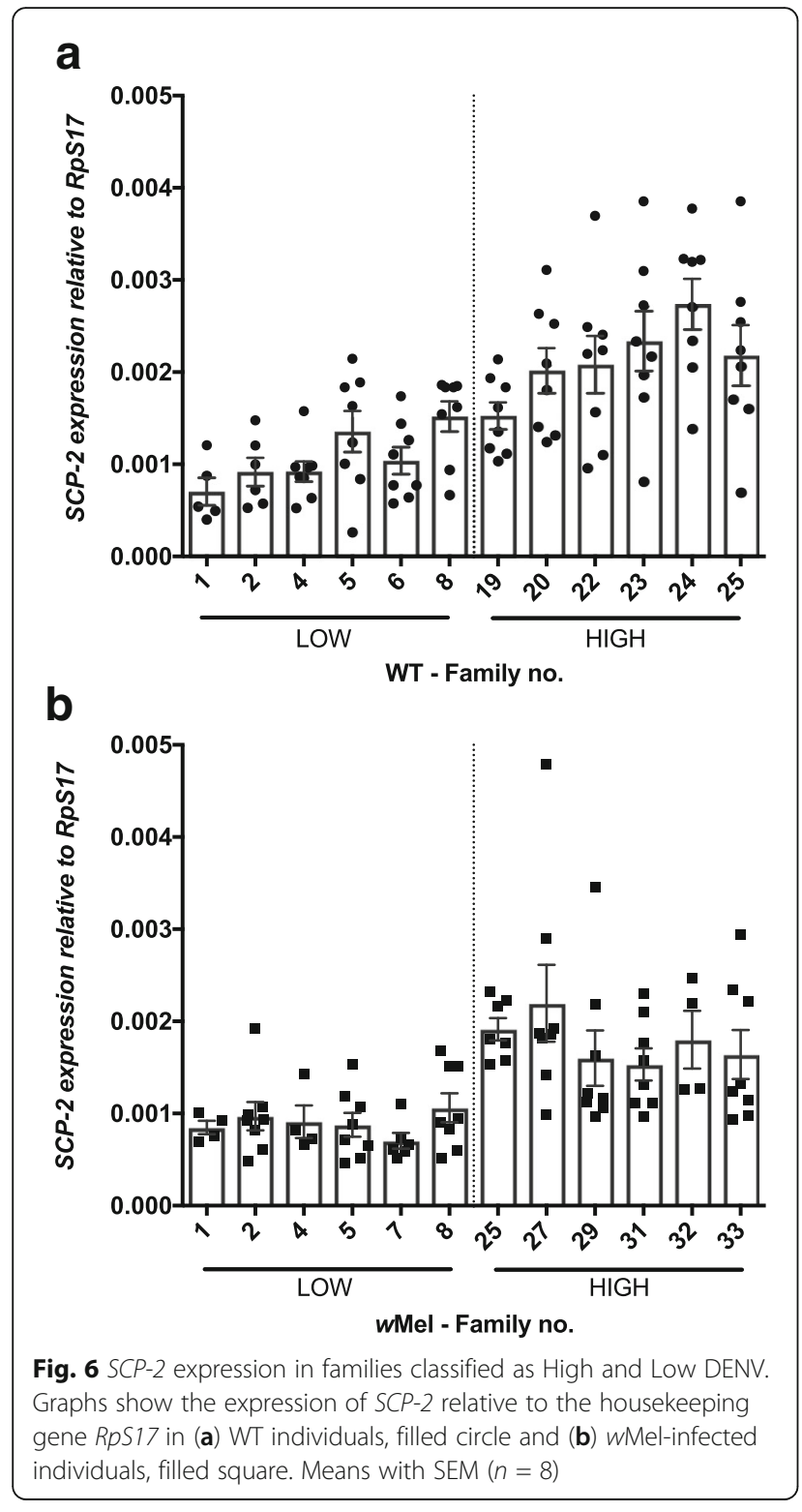

both host and symbiont we may be able to predict the outcome of co-evolutionary pressures. Interestingly, during a two-year period surveyed after release of the Wolbachia strain $w$ Mel into wild populations, neither host longevity nor DENV blocking showed evidence of change [23, 72].

First, if high densities of Wolbachia confer better blocking but those densities are detrimental to the host, we may expect selection for reduced loads or lowered maternal transmission rates. The detriment to the host may come from the costs of producing an immune response [73] or supporting a symbiont with complex metabolic needs [46, 74]. Additionally, there may be direct effects of damage on infected cells and tissues. The extreme form of this is demonstrated by the $w$ MelPop strain [75] that overgrows inside host cells and causes
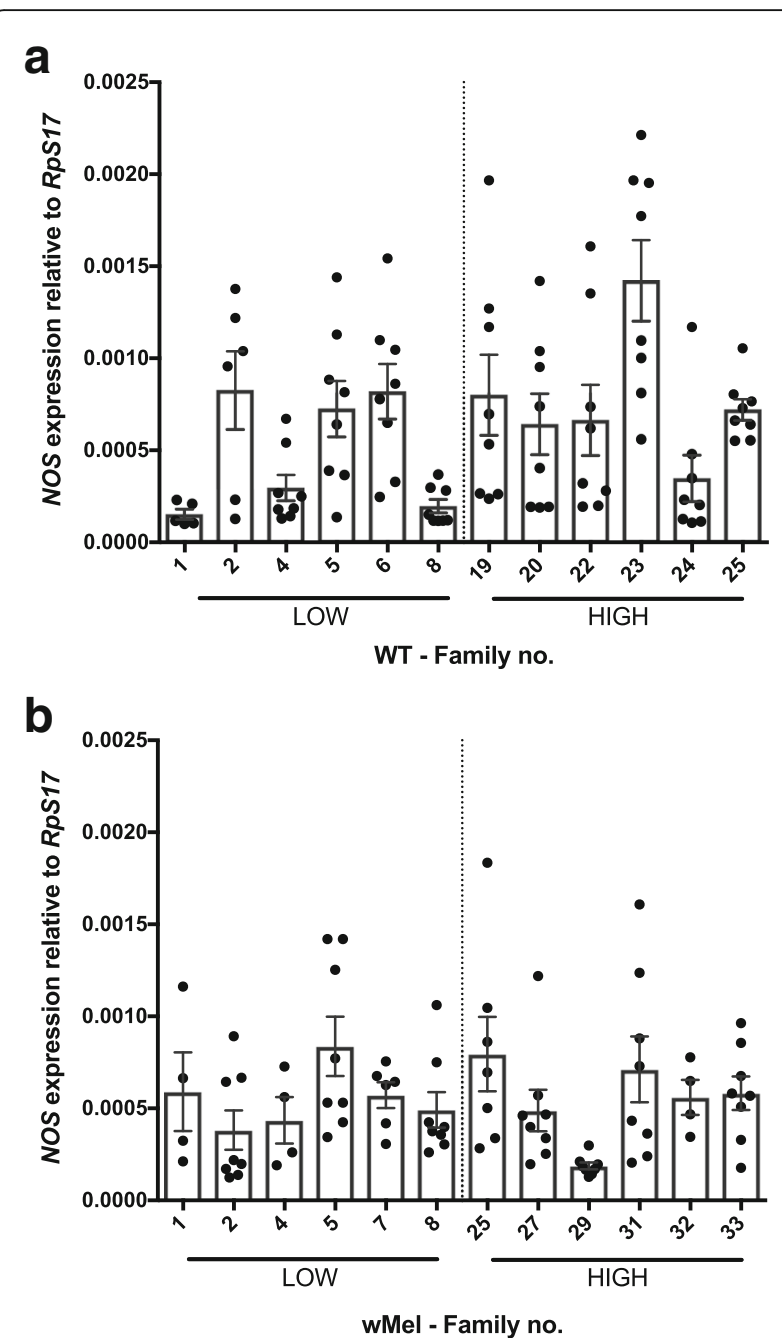

Fig. 7 NOS expression in families classified as High and Low DENV. Graphs show the expression of NOS relative to the housekeeping gene RpS17 in (a) WT individuals, filled circles and (b) wMel-infected individuals, filled squares. Means with SEM $(n=8)$

cell lysis, the result being shortened lifespan. While the other strains of Wolbachia being developed for biocontrol, $w \mathrm{Mel}$ and $w \mathrm{AlB}$, do not appear to cause cellular destruction, they still induce an immune response and spend a portion of their cellular resources on Wolbachia $[22,39]$. In the laboratory, these effects do not appear to have substantial impacts on the insect's reproductive output [72, 76]. Lastly, modelling has demonstrated that even with some negative fitness costs, the high maternal transmission and CI of Wolbachia will help it remain in populations [72].

Secondly, the impact of viral and other infectious agents on the insect may select for stronger blocking. Flaviviral infections can result in fitness costs for the mosquito; in the case of DENV, both reduced fertility and lifespan are affected [77]. Wolbachia-mediated blocking would attenuate these potential fitness costs 
associated to a high viral infection, as infection rates are lower in Wolbachia-infected mosquitoes and for those that become infected, severity is reduced [23]. Therefore, selection pressure for the blocking trait would be greater in areas with a high incidence of DENV and other flaviviruses. Additionally, there may be protection of native viruses [78] although it is unclear what impact these viruses have on host fitness if any. In D. melanogaster, the symbiont does not appear to affect native viral diversity [79]. Lastly, Wolbachia could protect against systemic bacterial, fungal or other parasitic infections, encountered by insects in the field, the nature of which are very poorly understood.

Using our extreme families with respect to DENV blocking, we were able to test for correlations for several candidate genes for the mechanism of blocking. Gene expression is highly plastic and if the blocking trait was reliant on Wolbachia-mediated modulation of some genes, the phenotype of the trait could vary rapidly due to co-evolution between Wolbachia and the mosquito [80]. Gene modulation in response to the symbiont is likely to be reduced greatly over time if the differences between novelly and natively infected hosts are predictive. For example, in Drosophila with long standing Wolbachia associations, the immune response is negligible [81]. We assessed genes involved in the humoral responses (vir-1 and $A G O 2$ ), intracellular lipid transport $(S C P-2)$ and nitrogen production (NOS). Interestingly, $A G O 2$ and $S C P-2$ showed a correlation between their levels of expression and DENV load, which reaffirms that they play a role in the viral infection. However, neither are sufficient to explain Wolbachia-mediated blocking of DENV infection [44]. The JAK/STAT effector vir-1 and NOS however, did not have patterns of expression related to strength of pathogen blocking trait. These data are in keeping with other studies [39, 53], suggesting that the immune response to Wolbachia, particularly present in novelly infected hosts, cannot explain a significant portion of blocking.

Several aspects of the study may limit its interpretation. As detailed above, the inheritance pattern of Wolbachia limits our ability to fully partition environmental and genetic variances. It also leads to correlations between DENV and Wolbachia loads in families. Regardless of this, the approach was able to limit the contribution of environmental influences by controlled breeding and infection of mosquitoes. Additionally, the approach used viral microinjection to infect mosquitoes due to the constraints of blood-feeding compliance and difficulties with obtaining disseminated infections in $w$ Mel-infected mosquitoes due to pathogen blocking. This method will not capture any of the variation in the trait associated with the midgut as it is bypassed by injection. However there is little evidence of strong
Wolbachia loads in the midgut [68] and it is not clear if this tissue contributes heavily to blocking. Also, we tested for DENV load at a single time point postinjection. Blocking phenotypes may vary with time, as would gene expression profiles [82]. It is plausible, for example, that gene expression levels for the candidate genes peak immediately after blood-feeding or exposure to the virus but decrease as soon as infection is established and viral replication promoted. Moreover, we only tested four candidate genes but for those that proved significant, further experiments such as RNAi-based knockdown or other gene modification techniques should be performed in adult mosquitoes to further elicit the contribution of both $A G O 2$ and $S C P-2$ to DENV infections.

\section{Conclusions}

In this study we demonstrated substantial variation in Wolbachia-mediated DENV blocking in mosquitoes that may spring from genetic contributions from both partners and environmental influences on Wolbachia, not controlled by family breeding. This suggests that the Wolbachia-mediated blocking may have the opportunity to evolve through time or be expressed differentially across diverse environments. The long-term efficacy of Wolbachia as a biocontrol tool will be dependent on the stability of blocking. We suggest the use of genome wide association studies to identify candidate genes that affect blocking. While the confounding of Wolbachia inheritance and environmental factors may lead to higher numbers of false positives, further functional testing using genetic modification would allow the isolation of key loci. Such broad genomic approaches offer the best means for identifying candidate pathways in the mosquito and Wolbachia without any a priori assumptions about how blocking might work. Understanding the mechanism of blocking will be necessary for the successful development of strategies [83] to counter the emergence of evolved resistance or variation in its expression under diverse conditions.

\section{Methods \\ Mosquito collection}

All Ae. aegypti mosquitoes collected from the field were identified by morphology and later checked by qPCR primer detection [12]. Two Ae. aegypti mosquito lines were used in this study: wildtype (WT) and Wolbachiainfected $(w \mathrm{Mel})$. WT are naturally Wolbachia free and their eggs were collected outside the Eliminate Dengue Wolbachia release zone [12] in greater Cairns, Australia, whereas eggs from the transinfected line $w$ Mel were collected from inside the same Wolbachia release zone and reared in the lab for 13 generations prior to the start of this study. Both lines were screened for presence/ 
absence of Wolbachia infection using the same qPCR methods. At every generation, wMel females were backcrossed to $20 \%$ uninfected WT males within 3 generations of the field to limit differences in genetic background while maintaining Wolbachia infection [24].

\section{Mosquito rearing and family design}

A modified full-sib [58, 59] breeding design was performed independently in WT and wMel Ae. aegypti mosquitoes. After synchronized egg hatching, mosquitoes were reared at a density of $\sim 150$ larvae in $30 \times 40 \times 8 \mathrm{~cm}$ trays containing $3 \mathrm{l}$ of $\mathrm{RO}$ water. Rearing was performed under controlled conditions of temperature $\left(26 \pm 2{ }^{\circ} \mathrm{C}\right)$, humidity ( $70 \%)$ and photoperiod (12:12, light:dark). Larvae were fed fish food (Tetramin, Melle, Germany). After pupation, males and females were sexed and transferred separately to $30 \times 30 \times 30 \mathrm{~cm}$ cages to allow eclosion at a density of $\sim 450$ individuals/cage. Adult mosquitoes were fed a $10 \%$ sucrose water diet. Six to eight day-old adult females (P1) were group fed on human volunteers. A total of 250 isofemale pairs containing a male and a blood-fed virgin female were placed in small housings. Eggs laid by isofemales on moist filter paper were collected every 2 days and dried uniformly for short-term storage. We chose families that produced more than 25 eggs that did not suffer from desiccation. F1 individuals from each family were hatched in deoxygenated water and interbred to increase the population number in F2. The experiment was performed using $25 \mathrm{WT}$ and $33 w \mathrm{Mel}$ independent families that produced sufficient numbers of eggs.

\section{Virus}

All experiments were carried out with a dengue virus serotype 2 strain (DENV-2, ET300) isolated from human serum collected from patients from East Timor in 2000. The virus was propagated in cell culture as described previously [84] before any experimental use. C6/36 cells were grown in RPMI 1640 media (Life Technologies, Carlsbad, CA, USA) and supplemented with 10\% heat-inactivated fetal bovine serum (FBS, Life Technologies), 1\% Glutamax (Life Technologies) and $25 \mathrm{mM}$ HEPES (Sigma-Aldrich, St. Louis, MO, USA). Cells were maintained in a non-humidified incubator at $25{ }^{\circ} \mathrm{C}$. prior to injection, C6/36 cells were grown to $70-80 \%$ confluence and ET300 infective virions were allowed to attach to the cells for $2 \mathrm{~h}$, washed and then maintained in 2\% FBS media. Virus was harvested at $7 \mathrm{dpi}$ by collecting the cell culture supernatant before centrifugation at $3200 \mathrm{rpm}$ for $15 \mathrm{~min}$ at $4{ }^{\circ} \mathrm{C}$. Viral stocks were stored in individual aliquots at $-80{ }^{\circ} \mathrm{C}$ until further use and titrated after using plaque assays.

\section{Intrathoracic microinjections}

DENV infected blood was injected to ensure uniformity of dosage that cannot be obtained by blood-feeding. $\mathrm{Ae}$ des aegypti females were briefly anesthetized with $\mathrm{CO}_{2}$ and DENV was injected under a microscope using a pulled glass capillary with a manual microinjector (Nanoject II, Drummond Sci., Broomall, PA, USA). Sixty-nine microlitres of diluted virus stock ( 70 DENV $\mathrm{pfu})$ were delivered intrathoracically into every $A e$. aegypti female. After injection, mosquitoes were maintained under identical initial controlled conditions at $25{ }^{\circ} \mathrm{C}$ with $60 \%$ relative humidity, $12 \mathrm{~h}$ light/dark cycle and feeding on a $10 \%$ sucrose solution.

\section{Dissection of tissues}

At 7-8 dpi, females were knocked down via $\mathrm{CO}_{2}$ and dissected in $1 \times$ phosphate buffered saline (PBS). Head, midguts and carcasses were dissected for 5-15 females per family. Dissecting needles were soaked in $80 \%$ ethanol between individual dissections to limit contamination. Different sets of needles were used for WT and $w$ Mel dissections. Dissected tissues were immersed in $200 \mu \mathrm{l}$ of TRIzol (Invitrogen, Carlsbad, CA, USA) in a $1.5 \mathrm{ml}$ tube containing a $3 \mathrm{~mm}$ glass bead (Merck KGaA, Darmstadt, Germany). Dissected samples were immediately placed on ice, lysed using a mini-beadbeater (BioSpec Products, Bartlesville, OK, USA), snap frozen and stored at $-80{ }^{\circ} \mathrm{C}$ until further processing. Any remaining injected mosquitoes per family were collected, frozen and stored at $-80{ }^{\circ} \mathrm{C}$ as whole insects.

\section{RNA/DNA extractions}

Head and carcass samples were extracted using the manufacturer's protocol for TRIzol reagent (Invitrogen). Both DNA and RNA phases were collected. RNA was quantified using a Synergy ${ }^{\text {ma }}$ MX microplate reader (Biotek, Winooski, VT, USA). All RNA samples were normalized by diluting to an even concentration of $10 \mathrm{ng} / \mu \mathrm{l}$ prior to analysis. Genomic DNA was stored at $-80{ }^{\circ} \mathrm{C}$, until subsequent extraction with back extraction buffer (4 M guanidine thiocyanate $+50 \mathrm{mM}$ sodium citrate $+1 \mathrm{M}$ Tris $\mathrm{pH}=8$ ) according to the manufacter's guidelines for Trizol (Invitrogen).

\section{DENV qRT-PCR and analysis}

All qPCR assays were run on a LightCycler480 Instrument (Roche Applied Science, Basel, Switzerland). Onestep quantitative RT-PCR (qRT-PCR) to detect DENV titres was performed using TaqMan Fast Virus 1-step Master Mix (Roche Applied Science) in a total of $10 \mu \mathrm{l}$, following manufacturer's instructions. Standards and samples were run in duplicate. Primer sequences used for DENV detection can be found in Additional file 1: Table S1. DENV qRT-PCR reactions were performed 
and run as described previously [44]. The number of viral copies present in each sample was evaluated using known standards [5]. The used standards ranged from $10^{8}$ to 10 DENV fragment copies. The limit of detection was set at 100 copies as the virus was consistently detected at this level. Concentration of DENV in each sample was extrapolated from the standard curve and back calculated to DENV copies/ $\mu$ g of total RNA.

\section{Analysis of genetic variance}

Genetic variance and subsequent broad-sense heritabilities $\left(\mathrm{H}^{2}\right)$ for the focal traits (DENV and Wolbachia load) were estimated using a modified full-sib breeding design and the following random effects linear model:

$$
z_{i j}=f_{i}+\varepsilon_{i j}
$$

where $z_{i j}$ is the trait value for the $j$ th female from the $i$ th family, $f_{i}$ is the random effect of the $i$ th family and $\varepsilon_{i j}$ is the unexplained error. To test whether genetic variance was greater than zero, model (1) was compared to a reduced model that had the family term omitted. A likelihood ratio test was constructed where twice the difference in log likelihood between the full and reduced models was contrasted with a Chi-squared distribution with one degree of freedom [85]. All models were fit using SAS version 9.3 (SAS Institute, Cary, NC, USA) separately on the wildtype and $w$ Mel-infected groups. Broad-sense heritability was calculated as twice the genetic variance $\left(\sigma_{\text {family }}\right)$ divided by the total phenotypic variance $\left(\sigma_{\text {family }}+\sigma_{\text {error }}\right)$.

\section{Candidate gene expression}

All carcass samples were retrotranscribed from RNA to cDNA using the SuperScript III Reverse Transcriptase kit (Invitrogen) containing $12.5 \mu \mathrm{l}$ of RNA template, $1 \mu \mathrm{l}$ of random primers (RP, $125 \mathrm{ng} / \mu \mathrm{l}), 1 \mu \mathrm{l}$ of deoxynucleotides (dNTPs, $2.5 \mathrm{mM}$ ), dithiothreitol (DTT), $5 \times$ buffer and enzyme as per kit instructions, totaling a volume of $20 \mu \mathrm{l}$. cDNA synthesis was performed in a C1000 Thermal Cycler (Bio-Rad, Hercules, CA, USA) on the following temperature profile: $5^{\prime}$ at $65^{\circ} \mathrm{C}$ followed by $10^{\prime}$ at $25^{\circ} \mathrm{C}, 50^{\prime}$ at $50{ }^{\circ} \mathrm{C}, 10^{\prime}$ at $75{ }^{\circ} \mathrm{C}$ and kept at $4{ }^{\circ} \mathrm{C}$. Gene expression levels were estimated using the SYBR Green I Master (Roche Applied Science) with $1 \mu \mathrm{l}$ of the previously synthesized cDNA, following manufacturer's instructions. All CT values were normalized to the housekeeping Ae. aegypti RpS17 gene [86], whose expression was consistent in different samples and mosquito lines. Expression ratios were obtained using the $\Delta \Delta \mathrm{Ct}$ method [87]. All primers for candidate genes are listed in Additional file 1: Table S1.

\section{Wolbachia quantification}

Wolbachia carcass densities were quantified after DNA extraction using a set of $w$ Mel-specific primers amplifying for the IS5 repeat element [88]. TaqMan multiplex qPCR was carried out following manufacturer's protocol (Roche Applied Science). The primers used can be found in Additional file 1: Table S1. Wolbachia to RpS17 housekeeping ratios were calculated using the $\Delta \Delta \mathrm{Ct}$ method [87].

\section{Statistics and data analysis}

All qPCR reactions throughout the study were run in duplicate and samples that failed to amplify both times were discarded as negative. Gene expression data were analyzed using a generalized mixed model with a random factor 'Family' nested with Wolbachia $\times$ DENV load, with both 'Wolbachia' and 'DENV load' set as fixed factors. Statistics were performed using IBM SPSS Statistics (v.23) and GraphPad Prism 6.

\section{Additional file}

Additional file 1: Table S1. Primers and probes used for qPCR gene detection. Gene IDs taken from VectorBase and UniProt. Figure S1. Head DENV loads correlate with Carcass DENV loads. DENV loads in the head were directly correlated to the same individual's DENV loads in the carcass using Pearson's correlation. Each dot depicts an individual either WT (blue, filled circles) or WMel-infected (green, filled squares). Figure S2. Head DENV loads negatively correlate with Wolbachia loads. Individual DENV loads were directly correlated to the same individual's Wolbachia loads using Pearson's correlation. Each square depicts an individual. Figure S3. Wolbachia loads after viral injection. No significant differences in Wolbachia levels were observed between media-injected mosquitoes (black) and virus-injected mosquitoes (green). Figure S4. Interaction plots on the expression of the four tested genes. Parallel lines show nointeraction occurring between main effects DENV Load (High/Low) and Wolbachia (+/-) (a, c). Non-parallel lines show strong interaction $(\mathbf{b}, \mathbf{d})$. (PDF 512 kb)

\section{Acknowledgments}

We wish to thank James Griffiths, Cassandra Koh, Henry Ye, Hilaria Amuzu and Emily Kerton for technical assistance and Scott Ritchie (James Cook University) for mosquito collections from the field.

\section{Funding}

The work was funded by the National Health and Medical Research Council of Australia (grant number: APP1103804) to EAM.

Availability of data and materials

The datasets analyzed during the current study are available in from Figshare. DOI: 10.4225/03/590032c579306.

\section{Authors' contributions}

The conceptualization and design of the experiment was done by EAM. Laboratory work was carried out by GT. Data analysis was performed by GT, SLA, SFC and EAM. The manuscript was written by GT and EAM. All authors read and approved the final manuscript.

\section{Ethics approval and consent to participate}

The ET300 DENV strain used in the study was received from researchers associated with Queensland Health $(\mathrm{QH})$, Australia/University of Queensland (UQ). IRB approval was obtained from UQ. Patient data were anonymized by $\mathrm{QH}$. The Monash University Human Research Ethics Committee gave ethical 
approval (permit CF11/0766-2011000387) for the experimental research. Human volunteer blood-feeders were provided and agreed upon written informed consent prior to the study.

\section{Consent for publication}

Not applicable

\section{Competing interests}

The authors declare that they have no competing interests.

\section{Publisher's Note}

Springer Nature remains neutral with regard to jurisdictional claims in published maps and institutional affiliations.

\section{Author details}

'School of Biological Sciences, Monash University, Clayton, Melbourne, VIC, Australia. ${ }^{2}$ School of Biological Sciences, The University of Queensland, QLD, St. Lucia, Australia

\section{Received: 15 August 2017 Accepted: 12 December 2017} Published online: 28 December 2017

\section{References}

1. Yen JH, Barr AR. The etiological agent of cytoplasmic incompatibility in Culex pipiens. J Invertebr Pathol. 1973;22(2):242-50.

2. Hedges LM, Brownlie JC, O'Neill SL, Johnson KN. Wolbachia and virus protection in insects. Science. 2008;322:702.

3. Teixeira L, Ferreira A, Ashburner M. The bacterial symbiont Wolbachia induces resistance to RNA viral infections in Drosophila melanogaster. PLoS Biol. 2008;6(12):e2

4. Kambris Z, Cook PE, Phuc HK, Sinkins SP. Immune activation by lifeshortening Wolbachia and reduced filarial competence in mosquitoes. Science. 2009;326(5949):134-6.

5. Moreira LA, Iturbe-Ormaetxe I, Jeffery JA, Lu G, Pyke AT, Hedges LM, et al. A Wolbachia symbiont in Aedes aegypti limits infection with dengue, chikungunya, and Plasmodium. Cell. 2009;139(7):1268-78.

6. van den Hurk AF, Hall-Mendelin S, Pyke AT, Frentiu FD, McElroy K, Day A, et al. Impact of Wolbachia on infection with chikungunya and yellow fever viruses in the mosquito vector Aedes aegypti. PLoS Negl Trop Dis. 2012;6(11):e1892.

7. McGraw EA, O'Neill SL. Beyond insecticides: new thinking on an ancient problem. Nat Rev Microbiol. 2013;11(3):181-93.

8. Hilgenboecker $\mathrm{K}$, Hammerstein $\mathrm{P}$, Schlattmann $\mathrm{P}$, Telschow A, Werren JH. How many species are infected with Wolbachia? - a statistical analysis of current data. FEMS Microbiol Lett. 2008;281(2):215-20.

9. Xi Z, Khoo C, Dobson SL. Wolbachia establishment and invasion in an Aedes aegypti laboratory population. Science. 2005;310:326-8.

10. McMeniman CJ, Lane RV, Cass BN, Fong AWC, Sidhu M, Wang Y-F, et al. Stable introduction of a life-shortening Wolbachia infection into the mosquito Aedes aegypti. Science. 2009:323:141-4.

11. Walker T, Johnson PH, Moreira LA, Iturbe-Ormaetxe I, Frentiu FD, McMeniman CJ, et al. The wMel Wolbachia strain blocks dengue and invades caged Aedes aegypti populations. Nature. 2011:476(7361):450-3.

12. Hoffmann AA, Montgomery BL, Popovici J, Iturbe-Ormaetxe I, Johnson PH, Muzzi F, et al. Successful establishment of Wolbachia in Aedes populations to suppress dengue transmission. Nature. 2011;476(7361):454-7.

13. Lambrechts L, Ferguson NM, Harris E, Holmes EC, McGraw EA, O'Neill SL, et al. Assessing the epidemiological effect of Wolbachia for dengue control. Lancet Infect Dis. 2015;15(7):862-6.

14. Gubler DJ, Suharyono W, Sumarmo, Wulur H, Jahja E, Saroso JS. Virological surveillance for dengue haemorrhagic fever in Indonesia using the mosquito inoculation technique. Bull World Health Organ. 1979;57(6):931-6.

15. Bennett KE, Olson KE, Munoz Mde L, Fernandez-Salas I, Farfan-Ale JA, Higgs $S$, et al. Variation in vector competence for dengue 2 virus among 24 collections of Aedes aegypti from Mexico and the United States. Am J Trop Med Hyg. 2002;67(1):85-92

16. Diallo M, Ba Y, Faye O, Soumare ML, Dia I, Sall AA. Vector competence of Aedes aegypti populations from Senegal for sylvatic and epidemic dengue 2 virus isolated in West Africa. Trans R Soc Trop Med Hyg. 2008;102(5):493-8.

17. $\mathrm{Ye}$ YH, Ng TS, Frentiu FD, Walker T, van den Hurk AF, O'Neill SL, et al. Comparative susceptibility of mosquito populations in North Queensland,
Australia to oral infection with dengue virus. Am J Trop Med Hyg. 2014; 90(3):422-30.

18. Whitehorn J, Kien DT, Nguyen NM, Nguyen HL, Kyrylos PP, Carrington LB, et al. Comparative susceptibility of Aedes albopictus and Aedes aegypti to dengue virus infection after feeding on blood of viremic humans: implications for public health. J Infect Dis. 2015;212(8):1182-90.

19. Bosio CF, Fulton RE, Salasek ML, Beaty BJ, Black WC. Quantitative trait loci that control vector competence for dengue-2 virus in the mosquito Aedes aegypti. Genetics. 2000;156:687-98.

20. Bennett KE, Flick D, Fleming KH, Jochim R, Beaty BJ, Black WC. Quantitative trait loci that control dengue-2 virus dissemination in the mosquito Aedes aegypti. Genetics. 2005;170(1):185-94.

21. Salazar MI, Richardson JH, Sanchez-Vargas I, Olson KE, Beaty BJ. Dengue virus type 2: replication and tropisms in orally infected Aedes aegypti mosquitoes. BMC Microbiol. 2007:7:9.

22. Bian $G, X u Y$, Lu P, Xie Y, Xi Z. The endosymbiotic bacterium Wolbachia induces resistance to denque virus in Aedes aegypti. PLoS Pathog. 2010;6(4): e1000833.

23. Frentiu FD, Zakir T, Walker T, Popovici J, Pyke AT, van den Hurk A, et al. Limited dengue virus replication in field-collected Aedes aegypti mosquitoes infected with Wolbachia. PLoS Negl Trop Dis. 2014:8(2):e2688.

24. Ye YH, Carrasco AM, Frentiu FD, Chenoweth SF, Beebe NW, van den Hurk $A F$, et al. Wolbachia reduces the transmission potential of dengue-infected Aedes aegypti. PLoS Negl Trop Dis. 2015;9(6):e0003894.

25. Dutra HL, Rocha MN, Dias FB, Mansur SB, Caragata EP, Moreira LA. Wolbachia blocks currently circulating zika virus isolates in brazilian Aedes aegypti mosquitoes. Cell Host Microbe. 2016;19(6):771-4.

26. Cho KO, Kim GW, Lee OK. Wolbachia bacteria reside in host Golgirelated vesicles whose position is regulated by polarity proteins. PLoS One. 2011;6(7):e22703.

27. Voronin D, Cook DAN, Steven A, Taylor MJ. Autophagy regulates Wolbachia populations across diverse symbiotic associations. Proc Natl Acad Sci USA. 2012;109(25):1638-46.

28. Ishmael N, Dunning Hotopp JC, loannidis P, Biber S, Sakamoto J, Siozios S, et al. Extensive genomic diversity of closely related Wolbachia strains. Microbiology. 2009:155(7):2211-22.

29. Kent BN, Bordenstein SR. Phage WO of Wolbachia: lambda of the endosymbiont world. Trends Microbiol. 2010;18(4):173-81.

30. Fenn K, Blaxter M. Wolbachia genomes: revealing the biology of parasitism and mutualism. Trends Parasitol. 2006:22(2):60-5.

31. Pichon S, Bouchon D, Cordaux R, Chen L, Garrett RA, Greve P. Conservation of the type IV secretion system throughout Wolbachia evolution. Biochem Biophys Res Commun. 2009;385(4):557-62.

32. Newton IL, Savytskyy O, Sheehan KB. Wolbachia utilize host actin for efficient maternal transmission in Drosophila melanogaster. PLoS Pathog. 2015;11(4):e1004798

33. Zug R, Hammerstein P. Bad guys turned nice? A critical assessment of Wolbachia mutualisms in arthropod hosts. Biol Rev Camb Phil Soc. 2015:90(1):89-111.

34. Vavre F, Fleury F, Lepetit D, Fouillet P, Bouletreau M. Phylogenetic evidence for horizontal transmission of Wolbachia in host-parasitoid associations. Mol Biol Evol. 1999;16(12):1711-23.

35. Woolfit M, Iturbe-Ormaetxe I, Brownlie JC, Walker T, Riegler M, Seleznev A, et al. Genomic evolution of the pathogenic Wolbachia strain, wMelPop. Genome Biol Evol. 2013:5(11):2189-204.

36. Weeks AR, Turelli M, Harcombe WR, Reynolds KT, Hoffmann AA. From parasite to mutualist: rapid evolution of Wolbachia in natural populations of Drosophila. PLoS Biol. 2007;5(5):e114.

37. Carrington LB, Hoffmann AA, Weeks AR. Monitoring long-term evolutionary changes following Wolbachia introduction into a novel host: the Wolbachia popcorn infection in Drosophila simulans. Proc R Soc B Biol Sci. 2010; 277(1690):2059-68

38. Terradas G, McGraw EA. Wolbachia-mediated virus blocking in the mosquito vector Aedes aegypti. Curr Opin Insect Sci. 2017:22:37-44.

39. Rances E, Ye YH, Woolfit M, McGraw EA, O'Neill SL. The relative importance of innate immune priming in Wolbachia-mediated dengue interference. PLoS Pathog. 2012:8(2):e1002548.

40. Pan X, Zhou G, Wu J, Bian G, Lu P, Raikhel AS, et al. Wolbachia induces reactive oxygen species (ROS)-dependent activation of the toll pathway to control dengue virus in the mosquito Aedes aegypti. Proc Natl Acad Sci USA. 2012;109(1):E23-31. 
41. Andrews ES, Crain PR, Fu Y, Howe DK, Dobson SL. Reactive oxygen species production and Brugia pahangi survivorship in Aedes polynesiensis with artificial Wolbachia infection types. PLoS Pathog. 2012:8(12):e1003075.

42. Ye YH, Woolfit M, Rances E, O'Neill SL, McGraw EA. Wolbachia-associated bacterial protection in the mosquito Aedes aegypti. PLoS Negl Trop Dis. 2013;7(8):e2362

43. Johnson KN. The impact of Wolbachia on virus infection in mosquitoes. Viruses. 2015;7(11):5705-17.

44. Terradas G, Joubert DA, McGraw EA. The RNAi pathway plays a small part in Wolbachia-mediated blocking of dengue virus in mosquito cells. Sci Rep. 2017;7:43847.

45. McGraw EA, Merritt DJ, Droller JN, O'Neill SL. Wolbachia density and virulence attenuation after transfer into a novel host. Proc Natl Acad Sci USA. 2002;99(5):2918-23.

46. Caragata EP, Rances E, Hedges LM, Gofton AW, Johnson KN, O'Neill SL, et al. Dietary cholesterol modulates pathogen blocking by Wolbachia. PLoS Pathog. 2013;9(6):e1003459.

47. Molloy JC, Sommer U, Viant MR, Sinkins SP. Wolbachia modulates lipid metabolism in Aedes albopictus mosquito cells. Appl Environ Microbiol. 2016;82(10):3109-20.

48. Caragata EP, Rances E, O'Neill SL, McGraw EA. Competition for aminoacids between Wolbachia and the mosquito host, Aedes aegypti. Microb Ecol. 2014;67:205-18.

49. Hussain M, Frentiu FD, Moreira LA, O'Neill SL, Asgari S. Wolbachia uses host microRNAs to manipulate host gene expression and facilitate colonization of the dengue vector Aedes aegypti. Proc Natl Acad Sci USA. 2011;108(22): 9250-5.

50. Zhang G, Hussain M, O'Neill SL, Asgari S. Wolbachia uses a host microRNA to regulate transcripts of a methyltransferase, contributing to dengue virus inhibition in Aedes aegypti. Proc Natl Acad Sci USA. 2013;110(25):10276-81.

51. Bhattacharya T, Newton ILG, Hardy RW. Wolbachia elevates host methyltransferase expression to block an RNA virus early during infection. PLoS Pathog. 2017;13(6):e1006427.

52. White PM, Serbus LR, Debec A, Codina A, Bray W, Guichet A, et al. Reliance of Wolbachia on high rates of host proteolysis revealed by a genome-wide RNAi screen of Drosophila cells. Genetics. 2017;205(4):1473-88.

53. Rainey SM, Martinez J, McFarlane M, Juneja P, Sarkies P, Lulla A, et al. Wolbachia blocks viral genome replication early in infection without a transcriptional response by the endosymbiont or host small RNA pathways. PLoS Pathog. 2016;12(4):e1005536.

54. Lu P, Bian G, Pan X, Xi Z. Wolbachia induces density-dependent inhibition to dengue virus in mosquito cells. PLoS Negl Trop Dis. 2012;6(7):e1754.

55. Osborne SE, Iturbe-Ormaetxe I, Brownlie JC, O'Neill SL, Johnson KN. Antiviral protection and the importance of Wolbachia density and tissue tropism in Drosophila simulans. Appl Environ Microbiol. 2012;78(19):6922-9.

56. Bian G, Zhou G, Lu P, Xi Z. Replacing a native Wolbachia with a novel strain results in an increase in endosymbiont load and resistance to dengue virus in a mosquito vector. PLoS Negl Trop Dis. 2013;7(6):e2250.

57. Dobson SL, Rattanadechakul W. A novel technique for removing Wolbachia infections from Aedes albopictus (Diptera: Culicidae). J Med Entomol. 2001;38(6):845-9.

58. Falconer DS, Mackay TFC. Introduction to quantitative genetics. 4th ed. Harlow: Longmans Green; 1996.

59. Ye YH, Chenoweth SF, Carrasco AM, Allen SL, Frentiu FD, van den Hurk AF, et al. Evolutionary potential of the extrinsic incubation period of dengue virus in Aedes aegypti. Evolution. 2016;70(11):2459-69.

60. Lambrechts L, Chevillon C, Albright RG, Thaisomboonsuk B, Richardson JH, Jarman RG, et al. Genetic specificity and potential for local adaptation between dengue viruses and mosquito vectors. BMC Evol Biol. 2009;9:160.

61. Dickson LB, Sanchez-Vargas I, Sylla M, Fleming K, Black WC. Vector competence in West African Aedes aegypti is flavivirus species and genotype dependent. PLoS Negl Trop Dis. 2014;8(10):e3153.

62. Kingsolver MB, Huang Z, Hardy RW. Insect antiviral innate immunity: pathways, effectors, and connections. J Mol Biol. 2013;425(24):4921-36.

63. Ramos-Castaneda J, Gonzalez C, Jimenez MA, Duran J, Hernandez-Martinez $\mathrm{S}$, Rodriguez $\mathrm{MH}$, et al. Effect of nitric oxide on dengue virus replication in Aedes aegypti and Anopheles albimanus. Intervirology. 2008;51(5):335-41.

64. Fu Q, Inankur B, Yin J, Striker R, Lan Q. Sterol carrier protein 2, a critical host factor for dengue virus infection, alters the cholesterol distribution in mosquito Aag2 cells. J Med Entomol. 2015;52(5):1124-34.
65. Fansiri T, Fontaine A, Diancourt L, Caro V, Thaisomboonsuk B, Richardson JH, et al. Genetic mapping of specific interactions between Aedes aegypti mosquitoes and dengue viruses. PLoS Genet. 2013;9(8):e1003621.

66. Chrostek E, Marialva MS, Esteves SS, Weinert LA, Martinez J, Jiggins FM, et al. Wolbachia variants induce differential protection to viruses in Drosophila melanogaster: a phenotypic and phylogenomic analysis. PLoS Genet. 2013; 9(12):e1003896.

67. Osborne SE, Leong YS, O'Neill SL, Johnson KN. Variation in antiviral protection mediated by different Wolbachia strains in Drosophila simulans. PLoS Pathog. 2009;5(11):e1000656.

68. Amuzu HE, McGraw EA. Wolbachia-based dengue virus inhibition is not tissue-specific in Aedes aegypti. PLoS Negl Trop Dis. 2016;10(11):e0005145.

69. Ferguson NM, Kien DT, Clapham H, Aguas R, Trung VT, Chau TN, et al. Modeling the impact on virus transmission of Wolbachia-mediated blocking of dengue virus infection of Aedes aegypti. Sci Trans Med. 2015;7(279):279ra237.

70. Nguyen TH, Nguyen HL, Nguyen TY, SN V, Tran ND, Le TN, et al. Field evaluation of the establishment potential of WMelPop Wolbachia in Australia and Vietnam for dengue control. Parasit Vectors. 2015;8:563.

71. Hoffmann AA, Sgro CM. Climate change and evolutionary adaptation. Nature. 2011;470(7335):479-85.

72. Hoffmann AA, Iturbe-Ormaetxe I, Callahan AG, Phillips BL, Billington $\mathrm{K}$, Axford JK, et al. Stability of the WMel Wolbachia infection following invasion into Aedes aegypti populations. PLoS Negl Trop Dis. 2014;8(9):e3115.

73. Koella JC, Boete C. A model for the coevolution of immunity and immune evasion in vector-borne diseases with implications for the epidemiology of malaria. Am Nat. 2003;161(5):698-707.

74. da Rocha Fernandes M, Martins R, Pessoa Costa E, Pacidonio EC, Araujo de Abreu L, da Silva Vaz I Jr, et al. The modulation of the symbiont/host interaction between Wolbachia pipientis and Aedes fluviatilis embryos by glycogen metabolism. PLoS One. 2014;9(6):e98966.

75. Yeap HL, Mee P, Walker T, Weeks AR, O'Neill SL, Johnson P, et al. Dynamics of the "popcorn" Wolbachia infection in outbred Aedes aegypti informs prospects for mosquito vector control. Genetics. 2011;187(2):583-95.

76. Axford JK, Ross PA, Yeap HL, Callahan AG, Hoffmann AA. Fitness of wAlbB Wolbachia infection in Aedes aegypti: parameter estimates in an outcrossed background and potential for population invasion. Am J Trop Med Hyg. 2016:94(3):507-16

77. Sylvestre G, Gandini M, Maciel-de-Freitas R. Age-dependent effects of oral infection with dengue virus on Aedes aegypti (Diptera: Culicidae) feeding behavior, survival, oviposition success and fecundity. PLoS One. 2013;8(3):e59933.

78. Zhang G, Etebari K, Asgari S. Wolbachia suppresses cell fusing agent virus in mosquito cells. J Gen Virol. 2016:97(12):3427-32.

79. Webster CL, Waldron FM, Robertson S, Crowson D, Ferrari G, Quintana JF, et al. The discovery, distribution, and evolution of viruses associated with Drosophila melanogaster. PLoS Biol. 2015;13(7):e1002210.

80. Ye YH, Chenoweth SF, McGraw EA. Effective but costly, evolved mechanisms of defense against a virulent opportunistic pathogen in Drosophila melanogaster. PLoS Pathog. 2009;5(4):e1000385.

81. Wong ZS, Hedges LM, Brownlie JC, Johnson KN. Wolbachia-mediated antibacterial protection and immune gene regulation in Drosophila. PLoS One. 2011;6(9):e25430.

82. Colpitts TM, Cox J, Vanlandingham DL, Feitosa FM, Cheng G, Kurscheid S, et al. Alterations in the Aedes aegypti transcriptome during infection with West Nile, dengue and yellow fever viruses. PLoS Pathog. 2011;7(9):e1002189.

83. Joubert DA, Walker T, Carrington LB, De Bruyne JT, Kien DH, Hoang Nle T, et al. Establishment of a Wolbachia superinfection in Aedes aegypti mosquitoes as a potential approach for future resistance management. PLoS Pathog. 2016;12(2):e1005434

84. Frentiu FD, Robinson J, Young PR, McGraw EA, O'Neill SL. Wolbachiamediated resistance to dengue virus infection and death at the cellular level. PLoS One. 2010;5(10):e13398.

85. Saxton AM. Genetic analysis of complex traits using SAS. Cary: SAS; 2004.

86. Cook PE, Hugo LE, Iturbe-Ormaetxe I, Williams CR, Chenoweth SF, Ritchie $\mathrm{SA}$, et al. The use of transcriptional profiles to predict adult mosquito age under field conditions. Proc Natl Acad Sci USA. 2006;103(48):18060-5.

87. Livak KJ, Schmittgen TD. Analysis of relative gene expression data using real-time quantitative PCR and the 2(-Delta Delta C(T)) method. Methods. 2001;25(4):402-8.

88. McMeniman CJ, Lane AM, Fong AW, Voronin DA, Iturbe-Ormaetxe I, Yamada R, et al. Host adaptation of a Wolbachia strain after long-term serial passage in mosquito cell lines. Appl Environ Microbiol. 2008;74(22):6963-9. 